University of Nebraska - Lincoln

DigitalCommons@University of Nebraska - Lincoln

Faculty Publications, UNL Libraries

Libraries at University of Nebraska-Lincoln

$9-2011$

Emerging Ideas on Emerging Technologies. A Report of the LITA Emerging Technologies Interest Group Discussion. American Library Association Midwinter Meeting, San Diego, January 2011

Kiyomi D. Deards

University of Nebraska-Lincoln, kdeards2@unl.edu

Kate Kosturski

JSTOR Outreach and Participation Services, New York, NY

Follow this and additional works at: http://digitalcommons.unl.edu/libraryscience

Deards, Kiyomi D. and Kosturski, Kate, "Emerging Ideas on Emerging Technologies. A Report of the LITA Emerging Technologies Interest Group Discussion. American Library Association Midwinter Meeting, San Diego, January 2011" (2011). Faculty Publications, UNL Libraries. 313.

http://digitalcommons.unl.edu/libraryscience/313

This Article is brought to you for free and open access by the Libraries at University of Nebraska-Lincoln at DigitalCommons@University of Nebraska - Lincoln. It has been accepted for inclusion in Faculty Publications, UNL Libraries by an authorized administrator of DigitalCommons@University of Nebraska - Lincoln. 
Published in Technical Services Quarterly 28:4 (2011), pp. 438-442

doi: 10.1080/07317131.2011.598065

Copyright (c) 2011 Routledge/Taylor and Francis. Used by permission.

Published online September 20, 2011.

\title{
Emerging Ideas on Emerging Technologies. A Report of the LITA Emerging Technologies Interest Group Discussion. American Library Association Midwinter Meeting, San Diego, January 2011
}

\author{
Kiyomi Deards ${ }^{1}$ and Kate Kosturski ${ }^{2}$ \\ 1. University of Nebraska-Lincoln, Lincoln, NE \\ 2. JSTOR Outreach and Participation Services, New York, NY
}

The LITA Emerging Technologies Interest Group meeting was conducted as a large roundtable discussion by the Interest Group Chair Jason Griffey with approximately 30-40 attendees. The purpose of the meeting was two-fold: (1) To discuss and share information about emerging technologies, and (2) to come up with potential topics and ideas for the Interest Group's program for the American Library Association's Annual Conference in New Orleans in June 2011.

Mr. Griffey began with an overview of last year's ALA annual program, "What is your library doing with Emerging Tech/What is an Emerging Technologies Librarian?" The 2011 ALA annual program should follow up with this general topic, expanding on ideas from the roundtable, but perhaps in a less formal and managed format than the 2010 program.

The audience was asked to consider the meaning of the term emerging technologies - not just what an emerging technology is, but how long a technology can be considered "emerging." In order to define "emerging" as well as "emerging technologies," the chair suggested members look toward the annual Horizon Report, ${ }^{1}$ published by the New Media Consortium and the EDUCAUSE Learning Initiative, for guidance. Examples of topics that may be considered emerging technologies, or already emerged technologies, include: the semantic web, location-based social networking, cloud computing, and mobile computing. The group was then asked to consider whether emerging technologies were defined by a timeline in which they were expected to reach the tipping point. These time- 
lines could be defined as: 1-2 years, 3 years, 4-5 years, and 10 years. Emerging technologies is a very subjective term, and it was suggested that thinking about how emerging technologies are defined would help ensure clarity and a common starting point for the discussion.

The discussion moved into an open forum format in which the attendees were asked to suggest program topics for the 2011 conference, with open invitation to demonstrate tools as needed. Discussion topics included:

1. Assistive emerging technologies. Examples include using iPads and smart phones to aid the visually impaired, people with dyslexia, and individuals suffering from brain disorders. The smaller screens of text on smart phones help those suffering from dyslexia read with significantly greater ease.

2. Augmented reality. Examples include using GPS devices, the monocle feature on Yelp's mobile application, and Quora (Android Monocle App). Ultra high frequency radio-frequency identification(UHF RFID) tags could be used to lead patrons to a specific book, and like a Geiger counter, indicate when they approach within a 10-foot radius of an item. High frequency radio-frequency identification (HF RFID) tags are the standard in libraries; the signals produced by these tags are much shorter in range. UHF RFID tags are used as an indoor global positioning system (GPS) in industry, but not in libraries. Advantages include taking a photo and receiving information. Privacy issues may be considered a barrier to use. Some libraries do not allow patrons to take pictures within the library.

3. Content management systems. An example is Drupal. Issues include design decisions needing to be made for all currently conceived aspects of the site before implementation; one template will not work for all pages. Several libraries face institutional barriers where their websites' software, host, and choice in layout are constrained by the parent organization. People want to contribute reviews, tag items, and interact with each other. How can we integrate these features into our catalog? Should we? People want to do everything in one website. How can we integrate all of our external services?

4. Cloud computing tools. Examples are Dropbox and Google Docs.

5. Citation and highlighting tools. Examples are Evernote, Instapaper, and Zotero.

6. Considering alternatives to the bookmarking tool Delicious in light of their (at the time) rumored shutdown. Examples include Kenmore and Diigo.

7. Location and entertainment based social networking. Examples include Foursquare, Gowalla, and Get Glue. Push technologies related to these tools were also discussed, such as approaching a library and receiving a list of the top 10 books that are currently on the shelf. Advantages capitalize on the popularity of stationary and mobile connectivity. Disadvan- 
tages include how to balance providing more services with the obligation to preserve users' privacy? Are we collecting too much information? How do we safeguard the information we collect?

8. Metadata and web standards. Examples include published descriptions at linking points using related item recommendations (URIs) based on search queries, VIVO, cataloging for research level use, Open ID, and Linked Data. Issues involved are that doing it right takes both time and money. To achieve maximum usefulness, we need to consider including more metadata, not less.

9. Mobile applications versus web based service: Which do we need, one or both?

10. Mobile websites: Issues include HTML 5 that separates the content from the presentation; this makes it easier to control the mobile version separately from the web version, and should improve the quality and functionality of mobile websites.

11. Open Application Programming Interface (APIs) - aka Web 2.0 applications - that allow websites to interact with each other. Examples include Open Social and the Facebook platform.

12. Quick Response (QR) Codes. Advantages include a great deal of information that can be stored in a small space.

13. Wireless technologies and linking devices. Examples include printers, laptops, and scanners. Issues are cost, security, and fair allocation of resources so that all entitled users have equitable access.

Other topics mentioned:

- Aardvark. This is a question answering service, similar to chat reference. People submit questions at the website (http:/ / vark.com), by IM, e-mail, Twitter, or iPhone application, and it searches your friends and people with similar interests for someone to answer your question. It is also possible to sync a Facebook profile via Facebook connect, allowing the application to connect users with friends-of-friends to help answer a posed question. People who are contacted for an answer to a question indicate whether they are willing to and available to answer the question by selecting "Yes, No, or Busy."

- Jing. This website allows users to share video or photos. It was suggested that librarians could upload items to this service when helping a patron by e-mail or chat. Advantages include Quick link generation, and it is free. You can upload a screen cast, up to 5 minutes in length, with sound, and put the link anywhere online or send it as a link in an e-mail or on chat.

The discussion also included potential topics for ALA annual that did not relate to specific tools including: project management skills and the psychology of emerging technologies. 
A session on project management skills would provide best practices for implementing ideas and getting buy-in from other departments in your institution (e.g., IT department, marketing). Other topics that could be addressed by this session include:

- Learning how to speak and understand "tech" for project managers.

- How to prepare and build support outside your unit without moving too fast.

- Seeing the project from other perspectives, ranging from top-level administrators to end-users.

- When, and how, to ask for help to prevent burnout and mistakes, and discovering what are the best channels to go through to accomplish your goal.

- Who should collaborate in the development process? Your institution only or corporate sponsors? Should your project be open source, commercialized, or private use for your institution only?

A panel on the psychology of emerging technologies may involve answering questions such as: Why are we so resistant to change? What is your technology philosophy? Examples include (1) Locking your system down as much as possible. In a large system a problem can spiral faster and cause more work than in a small system. Does system size play a role in risk tolerance? And (2) Leaving your system open and plugging holes as they happen. Approaching life from the worst-case scenario can be a mistake and tie up resources.

Additional topic suggestions included:

- Who in the organization can we turn to for guidance?

- What are emerging technologies?

- How can companies and libraries communicate and form partnerships to create new advances and develop new programs, applications, and technologies?

- How can we embrace beneficial change, but avoid change for the sake of change?

In closing Mr. Griffey informed attendees that LITA was in the process of forming a Linked Data interest group to study trends, implications, and potential impact of Linked Data with an emphasis on the work being done with new authority files by the Library of Congress. Griffey also reminded the group that this interest group has led to growth in LITA - the Mobile Computing Interest Group was also created as a spin off from this group, demonstrating the significant role the Emerging Technologies Interest Group plays in predicting future technologies of interest to LITA. 


\section{Note}

1. The 2011 Horizon Report can be viewed online at http://www.educause.edu/Resources/2011HorizonReport/223122 